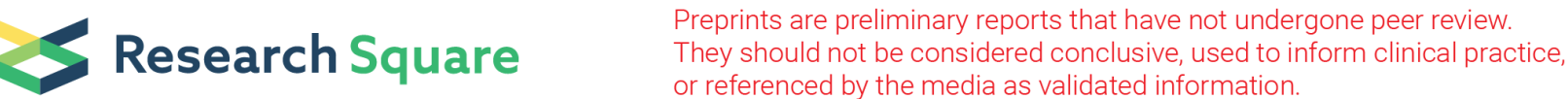

\section{Cigarette smoking and all-cause mortality in rural Chinese male adults:15-year follow-up of the Anqing cohort study}

Lijing Ye

China Pharmaceutical University https://orcid.org/0000-0002-7383-4239

Jie Yang

China Pharmaceutical University

Jingyi Li

China Pharmaceutical University

Nannan Cheng

China Pharmaceutical University

Yue Zhang

China Pharmaceutical University

Xiaofan Lu

China Pharmaceutical University

Ziyi Zhou

China Agricultural University

Zhuo Wang

China Agricultural University

Lishun Liu

China Agricultural Universiyt

Xiao Huang

Nanchang University Second Affiliated Hospital

\section{Yun Song}

China Agricultural University

Shibo Xing

Health Center of Dongguo

Dongqing Wang

Panjin People's Hospital

Junnong Li

Weinan Central University

Binyan Wang

Anhui Medical University

Genfu Tang 
Anhui Medical University

\section{Xianhui Qin}

Southern Medical University

\section{Pierre Zalloua}

Lebanese American University

\section{Huisheng Zhang}

Shenzhen University

\section{Fangrong Yan ( $\nabla$ f.r.yan@163.com )}

https://orcid.org/0000-0003-3347-5021

\section{Xiping Xu}

Southern Medical University

\section{Research article}

Keywords: smoking status, mortality, Chinese rural area

Posted Date: December 28th, 2020

DOI: https://doi.org/10.21203/rs.3.rs-50083/v2

License: (1) (1) This work is licensed under a Creative Commons Attribution 4.0 International License. Read Full License

Version of Record: A version of this preprint was published at BMC Public Health on April 9th, 2021. See the published version at https://doi.org/10.1186/s12889-021-10691-2. 


\section{Abstract}

Background - According to the Global Burden of Disease Study 2017, smoking is one of the leading four risk factors contributing to deaths in China. We aimed to evaluate the associations of smoking with allcause mortality in a Chinese rural population.

Methods-Male participants over age $45(n=5,367)$ from a large familial aggregation study in rural China, were included in the current analyses. A total of 528 former smokers and 3849 current smokers accounted for $10 \%$ and $71.7 \%$ of the cohort, respectively. Generalized Estimating Equations were used to evaluate the association between baseline smoking status and mortality, adjusting for pertinent covariates.

Results-There were 579 recorded deaths during the 15-year follow-up. Current smokers (odds ratio $[\mathrm{OR}], 1.60 ; 95 \% \mathrm{Cl}, 1.23-2.08)$ had higher all-cause mortality risks than nonsmokers. Relative to nonsmokers, current smokers of more than 40 pack-years ([OR],1.85; 95\% Cl,1.33-2.56) had a higher allcause mortality risk. Compared to nonsmokers, current smokers who started smoking before age 20 ([OR],1.91; 95\% Cl,1.43-2.54) had a higher all-cause mortality risk, and former smokers in the lower packyear group who quit after age 41 (median) ([OR],3.19; 95\% Cl,1.83-5.56) also had a higher risk of death after adjustment. Furthermore, former smokers who were also former drinkers had the highest significant risk of mortality than people who never smoke and drink. $(P$ for interaction $=0.034)$.

Conclusions -This study provides evidence that current smokers or former smokers have higher mortality risk than nonsmokers and would benefit from cessation at a younger age.

\section{Introduction}

Smoking is a leading, but avoidable, causes of premature deaths and disability globally ${ }^{1}$, contributing to an estimated six million deaths worldwide in 2010 , including one million in China. The World Health Organization projects that by 2030 tobacco-attributable deaths will annually account for 3 million deaths in industrialized countries and 7 million in developing countries. China now consumes about $40 \%$ of the world's total cigarettes, predominantly by men, with a large increase in consumption occurring in urban rather than rural areas over the past three decades 234 . During the past 20 years, a slight decrease in smoking prevalence was observed in the general Chinese population the success rate of smoking cessation was only $14.4 \%$, has no significant change compared to $2010^{5}$. An awareness of the harms of cigarette smoking and the diseases it can cause showed no obvious change from the cessation rates. Despite tobacco control, cigarette use remains the leading cause of premature mortality in China and globally. The 2017 Global Burden of Diseases, Injuries, and Risk Factors Study (GBD) estimated that high systolic blood pressure, smoking and a diet high in sodium were the top three risk factors for number of deaths in 2017 in China. They were also the leading risk factors for disability-adjusted life-years (DALYs) in China overall and in 21 provinces, and were either second or third in all remaining provinces ${ }^{6}$. 
The hazards of smoking have been documented over the past 55 years, providing sufficient evidence of a causal relationship between smoking and many types of death ${ }^{7}$. A total of 160,113 participants of the $\mathrm{NIH}-A$ ARP Diet and Health Study aged $>70$ years showed that relative to never smokers, current smokers were more likely to die during follow-up (hazard ratio, 3.18; $95 \% \mathrm{Cl}, 3.04-3.31)^{8}$. For participants who were 25 to 79 years of age in the U.S. National Health Interview Survey, the rate of death from any cause among current smokers was about three times that of those who had never smoked (hazard ratio for men, $2.8 ; 99 \% \mathrm{Cl}, 2.4-3.1)^{9}$. Early initiation of smoking is also related to increased mortality from all causes and disease-specific causes, such as vascular diseases (cardiovascular, coronary artery disease, cerebrovascular disease); respiratory diseases; and cancers ${ }^{10}$. In addition, the mortality risk associated with smoking cessation is decreased compared with continuing smokers after 12 years of follow-up in the Nurses' Health Study. ${ }^{7}$

The China Health and Nutrition Survey (CHNS) study indicated that the current smoking rate in rural villages has remained relatively stable across the past two decades from 2000 (about $50-55 \%$ ). The rate in urban neighborhoods decreased from 1991 to 2009 , and then slightly increased to $25 \%$ in $2011^{11}$. Residents living in socially and economically developed regions were less likely to smoke than those living in remote and underdeveloped regions. Those with lower levels of education and engaging in farm work were also more likely to smoke ${ }^{12}$.The urban population's awareness of the above three diseases caused by smoking was higher than that in rural areas, with significant differences.

In the past two decades, the rate of cigarette smoking in rural areas has remained stable (nearly 50\%), but it has fallen by approximately $1.1 \%$ annually in urban communities. After adjusting individual and community characteristics, the smoking prevalence makes little differences statistically ${ }^{11}$. Trends in cigarette smoking are a signal of health inequalities. Meanwhile, the common reasons for quitting include existing medical concerns, prevention for future health problems, family stress and financial consideration ${ }^{13}$. Few people choose cessation under the advice of media advertisements or slogans. Among some mainstream media, over one- third of men reported not having paid attention to any health warnings about smoking hazards, who are higher in the elderly, in rural areas or with lower education. At the same time, cigarette consumption for gifting and sharing during New Year's Festival remains prevalent in rural neighborhoods. Among current and former smokers, sharing cigarettes is a major obstacle to quitting ${ }^{13}$.

To date, most studies of cigarette smoking and mortality have focused on all-aged populations in the US, Australia and Korea 1481516 with few studies examining the impact of tobacco use on disease and mortality risk among the middle-aged and elderly in China, especially in rural areas. To address this lack of evidence, we aimed to examine the association between smoking status with all-cause mortality among smokers and non-smokers using data from the osteoporosis cohort, which enrolled participants from Anqing, Anhui province, a rural area in Eastern China, in 2003.

\section{Methods}




\section{Study design and participants}

This study is part of a large community-based cohort initiated in 2003 among residents of Anhui Province, China ${ }^{17}$. The major exclusion criteria included history of type 1 diabetes; renal failure; chronic infections such as tuberculosis or other infectious diseases; malignancies; rickets or other metabolic bone diseases; chronic glucocorticoid use; viral cirrhosis; and thyrotoxicosis.

A total of 18,237 adults participated in the baseline study were re-surveyed with a mean follow-up interval of 14.1 years. 8995 female participants were excluded from this analysis because the number of current and former smokers in the female population was too small to allow for regression analysis. After excluding participants with missing data on smoking status, pack-years of cigarette smoking, family numbers and anyone whose age was below 45 years, the final cohort consisted of 5,367 male participants. All smokers were cigarette smokers.

The study was approved by the Institutional Review Boards of the Anhui Medical University. Written approved informed consent was obtained from each participant. The data supporting the findings of this study will be available from the corresponding author (Xiping $\mathrm{Xu}$ ) on request.

\section{Death Outcome Collection}

Follow-up visits with interviews and data collection were conducted in 2010, 2011, 2014, 2017 and 2018. Data on death was obtained by telephone or face-to-face interviews with participants or household members (if deceased).

\section{Smoking Status, Smoking Intensity, Age of Smoking Initiation and Cessation Age}

Smoking status was self-reported by respondents and coded into three categories: current, former, and non-smokers. Current smokers reported smoking more than 10 packs in their lifetime and currently smoke every day or most days. Former smokers reported having smoked 10 packs or more cigarettes in their lifetime but currently have ceased. Non-smokers reported smoking fewer than 10 packs in their entire life. Current smokers were further disaggregated by pack-years ${ }^{18}$ using the equation:

Pack-years $=(\text { Cigarettes per day } / 20)^{\star}$ years smoked

Pack-years was further divided into three categories $(<20,20-40, \geq 40)^{19}$, and as a binary variable where it was divided at the median for analysis. We disaggregated former smokers by years since smoking cessation ( $\nabla 55$, and $\geq 55$ years-old), and age of smoking initiation (for current smokers) which was divided into two groups ( $₫ 20$, and $\geq 20$ years-old).

\section{Statistical Analysis}

Means (SD) or medians (25th percentile-75th percentile) and proportions were calculated for population characteristics by smoking status. Differences between groups were achieved with analysis of variance. 
In the multivariate models, we adjusted for age, body mass index (BMI), systolic blood pressure (SBP), diastolic blood pressure (DBP), drinking status, fasting glucose (GLU), total cholesterol (TC), triglycerides (TG), high-density lipoprotein cholesterol (HDL-C) education level and occupation using Generalized Estimating Equations (GEE) to evaluate the association between baseline smoking status and mortality. Variables in the stratified analysis included BMI (Tertile $<20,20-21.9, \geq 20 \mathrm{~kg} / \mathrm{m}^{2}$ ), age (Tertile $<51.3$, $\geq 51.3$ years), $\operatorname{SBP}(<130,130-140, \geq 140 \mathrm{mmHg}$ or history of hypertension), $\mathrm{DBP}(<80,80-90, \geq 90 \mathrm{mmHg}$ or a history of hypertension), and drinking status (never, former, current).

A two-tailed $P<0.05$ was considered statistically significant in all statistical analyses. EmpowerStats (http://www.empowerstats.com) and RStudio software (Version 1.2.5033, http://www.R-project.org/) were used for all statistical analyses.

\section{Results}

\section{Study Participants and Baseline Characteristics}

Baseline characteristics of the participants according to smoking status (nonsmoker, former smoker and current smoker) are summarized for all males in Table 1. During the 15-year follow-up, the mean ages were 52.3(mean)4.8(SD), 52.5(mean)4.6(SD) and 52.0(mean)4.6(SD) for nonsmokers, former smokers, and current smokers, respectively. We found that current smokers tended to be younger and have lower blood pressure, body mass index, glucose, total cholesterol and triglycerides levels compared with nonsmokers (Table 1). The results were not similar in women for fewer current smokers. Of 8,995 women enrolled in our study, only $2.4 \%$ were current smokers, including $0.2 \%$ who stopped. (Supplemental Table 2).

\section{Effects of Smoking Status on Mortality}

We observed a positive association between baseline pack-years and risk of death (logOR) after adjustment (Figure $1 \mathrm{~A}$ ). Figures $1 \mathrm{~B}$ and $1 \mathrm{C}$ show that younger smoking initiation age and older smoking cessation age were associated with a higher risk of death. The graph displays a decrease in mortality risk as smoking initiation age increases, while as smoking cessation age increases there is an increase in death risk. This finding was further evaluated by GEE models as shown in Table 2. Current cigarette smokers (odds ratio ([OR], 1.60; $95 \% \mathrm{Cl}, 1.23,2.08, \mathrm{P}<0.001$ ) and former smokers ([OR], $2.12 ; 95 \% \mathrm{Cl}$, $1.49,3.01, \mathrm{P}<0.001)$ had higher all-cause mortality risk than non-tobacco users. Relative to nonsmokers, current smokers of fewer than 20 pack-years ([OR], 1.18; 95\% Cl, 0.85,1.64, $\mathrm{P}=0.314), 20$ to 40 pack-years ([OR], 1.69; 95\% Cl, 1.28-2.23, $\mathrm{P}<0.001)$ and more than 40 pack-years ([OR], 1.85; 95\% Cl, 1.33,2.56, $\mathrm{P}<0.001)$ had a higher all-cause mortality risk.

\section{Effects of Smoking Initiation Age and Smoking Cessation Age on Mortality}

For smoking initiation age, compared with nonsmokers, current smokers who began smoking before age 20 had a $91 \%([O R], 1.91 ; 95 \% \mathrm{Cl}, 1.43,2.54 ; \mathrm{P}<0.001)$ increased risk for death, and those who began after 
age 20 ([OR],1.39; 95\%Cl, 1.06,1.84; $\mathrm{P}=0.019)$, had a $39 \%$ increased risk of death. The results were consistent across the high and low pack-year groups (Table 3 ). Those whose smoking cessation age was older than 55 year-old had a $296 \%$ ([OR], 3.96; 95\%Cl, 1.03,15.14; $\mathrm{P}=0.045)$ and $158 \%$ ([OR], 2.58; 95\% $\mathrm{Cl}$, $1.18,5.63 ; P=0.018$ ) increased risk for death in the low vs. high pack-year groups, respectively (Table 4).

\section{The Joint Effect between Drinking and Smoking on Mortality in Males}

After adjustment, we found that current drinkers who did not smoke had an insignificantly $42 \%$ ([OR], $0.58 ; 95 \% \mathrm{Cl}, 0.32,1.05 ; \mathrm{P}=0.072$ ) decreased risk for death compared to nondrinkers who did not smoke. Those who were both former drinkers and former smokers ([OR], 6.40; 95\% $\mathrm{Cl}, 3.03,13.50 ; \mathrm{P}<0.001$ ) had an all-cause mortality risk of more than five times higher than nondrinkers who did not smoke. Regardless of drinking status, the ever-smoking population showed an upward trend in mortality (Table 5). We further performed stratified analyses to assess the effects of smoking status (never, former and current) on death in various subgroups (Supplemental Table 1).

\section{Discussion}

Our study provides further support that current and former smokers experienced greater risk of death at follow-up than nonsmokers in a Chinese rural population. Younger age at smoking initiation and older age at smoking cessation were both associated with increased risk of mortality.

Risk of all-cause mortality was significantly higher in former or current smokers than in nonsmokers. This finding parallels results from The National Longitudinal Mortality Study ${ }^{20}$. Another study with a mean (SD) follow-up of 6.6 (1.3) years from the National Institutes of Health-AARP Diet and Health Study ${ }^{21}$, showed more powerful evidence. There was a dose-dependent association between reported number of CPD (cigarettes per day) at baseline with all-cause mortality as well as with deaths from examined smoking-related outcomes. Even those who reported smoking fewer than $1 \mathrm{CPD}(\mathrm{HR}, 1.99 ; 95 \% \mathrm{Cl}, 1.76$, $2.25)$ or 1 to $10 \mathrm{CPD}(\mathrm{HR}, 2.60 ; 95 \% \mathrm{Cl}, 2.45,2.75)$ had an increased risk of all-cause mortality. Importantly, it extends these findings to show that risk of death associated with smoking remains consistent even for low intensity smoking.

Our study results are striking in that relatively small differences in age at initiation were associated with strong differences in mortality risk 15 years later. A National Health Interview Survey showed that early smoking initiation before age 13 was associated with increased risks for cardiovascular/metabolic (OR:1.67) and pulmonary (OR:1.79) diseases as well as smoking-related cancers (OR:2.1) among current smokers; the risks among former smokers were cardiovascular/metabolic (OR:1.38); pulmonary (OR:1.89); and cancers (OR:1.44). Elevated mortality was also related to early smoking initiation among both current (hazard ratio, 1.18) and former smokers $(H R=1.19){ }^{10}$. Relative to former smokers, the risk of mortality was lower in individuals who quit smoking at earlier ages. This finding is in agreement with the Sax Institute's 45 and Up Study ${ }^{16}$. Smoking cessation remains beneficial even at age 50 . The investigation based on 489,066 participants, aged $\geq 60$ years, from 22 population-based cohorts of the 
CHANCES Consortium confirmed that for former smokers, excess mortality and risk advancement periods (RAPs) decreased with time since cessation, with RAPs of $3.9(95 \% \mathrm{Cl}, 3.0,4.7), 2.7(95 \% \mathrm{Cl}, 1.8,3.6)$, and $0.7(95 \% \mathrm{Cl}, 0.2,1.1)$ for those who had quit $<10,10$ to 19 , and $\geq 20$ years ago, respectively ${ }^{22}$. Similarly, the Zutphen Study found that in 1373 men, stopping cigarette smoking at age 40 increased the life expectancy by 4.6 years, while the number of disease-free life-years was increased by 3.0 years ${ }^{23}$.

To date, most studies about smoke had been focused on urban or general population ${ }^{24}$, only limited studies on smoking and mortality risk have been carried out in Chinese rural areas and in particular none have such a long and large prospective cohort among a male farming population as the current study. Consistently for all these studies, with the increase in pack-years in current smokers, all-cause mortality climbed remarkably. Although the majority of results follow a similar path, our study showed contrary results in former smokers. It is likely that among men who had stopped smoking due to illness, the protective effects of quitting cannot be assessed straightforwardly, even if cessation is substantially protective, because the underlying illness that prompted the smoking cessation may cause a misleadingly elevated risk. The question remains: how does tobacco attribute to all-cause mortality? The "China reported health hazards of smoking" pointed out that tobacco smoke contains 69 known carcinogens, which can cause mutations in key genes, dysregulate normal growth control mechanisms, and eventually lead to the occurrence of cell cancer and malignant tumors ${ }^{25}$. In addition, it also damages vascular endothelial function, which can lead to the occurrence of atherosclerosis, narrowing of the arterial vascular cavity and cause a variety of cardiovascular and cerebrovascular diseases.

Our study has two new findings. Firstly, the age of first tobacco use is an important determinant of mortality risk. Age at smoking initiation was strongly associated with mortality in men over 45 years of age. Ever smokers who started smoking earlier were at a progressively higher risk of mortality during follow-up, relative to those who started smoking later. Similarly, risk of mortality was lower when cessation occurred at an earlier age. This finding supports analogous results abroad. A possible reason is that an earlier age of smoking initiation and a later age of smoking cessation, increases duration of exposure. Secondly, our results suggest that nonsmokers who were ever drinkers, had a potent protective factor for mortality risk in this rural Chinese population. While, former smokers who were former drinkers were at risk. We surmise that the increase in mortality risk for those who previously used cigarettes and alcohol among this rural population could be a result of stopping usage due to illness. Because of the cessation patterns in rural areas are different from those in cities, ordinary cessation methods cannot effectively prevent the beginning of smoking and fail to induce residents to quit. For example, indoor smoking bans may not have a substantial impact on middle-aged and elderly people in rural areas, because the majority of them are farmers who worked outsides. Raising the tobacco sales tax may push them to purchase cheaper cigarettes, because the cigarette prices in China vary greatly. Hence if interventions are adopted to the situations and demands for this populations, the protection in rural villages will be more effective, particularly in the context of unbalanced social and economic development ${ }^{11}$. 
This study has specific strengths and limitations. Firstly, the data were sparse after stratification, resulting in a larger $95 \%$ confidence interval and insignificant results. Secondly, in rural China, smoking cessation was motivated mainly by health issues experienced either directly or indirectly. Nearly all participants who have attempted or successfully quit smoking reported experiencing some health issues prior to quitting. And those who successfully quit frequently reported significant health events that prompted a visit to a doctor ${ }^{26}$. Lastly, only smoking information collected at baseline was available for this analysis, therefore, it is possible that recall bias existed and some participants who were former smokers at baseline may have resumed smoking afterward, leading to an underestimation of benefits related to smoking cessation. Another weakness of the study was the lack of classification and time of death. Data on smoking-attributable causes of death would have been informative in our interpretation of these results.

\section{Conclusion}

We provide further evidence that cigarette smoking, regardless of amount, confers significant mortality risks, and that pack-years and age of smoking initiation and cessation, both key components of smoking duration, are important predictors of mortality in Chinese rural adults aged 45 years and older. Younger age at initiation was associated with increased risk of mortality, highlighting the seriousness of the impact that young adult smoking has on lifetime mortality risk. Therefore, smoking cessation incentives and the health benefits of nonsmoking should be promoted and emphasized to youth and all smokers, regardless of age.

\section{Abbreviations}

$S B P=$ systolic blood pressure

$D B P=$ diastolic blood pressure

$G E E=$ generalized estimating equations

$B M I=$ body mass index

$T C=$ total cholesterol

$T G=$ triglycerides

$H D L-C=$ high-density lipoprotein cholesterol

$\mathrm{Cl}=$ indicates confidence interval

$O R=$ odds ratio

\section{Declarations}




\section{Ethics approval and consent to participate}

The study was approved by the Institutional Review Boards of the Anhui Medical University. Written approved informed consent was obtained from each participant.

\section{Consent for publication}

Not applicable.

\section{Availability of data and materials}

The data supporting the findings of this study will be available from the author (Xiping Xu) on request.

\section{Competing interests}

All authors have completed the ICMJE uniform disclosure form and have declared the following:

Dr. Xiping Xu reports grants from the National Key Research and Development Program [2016YFE0205400, 2018ZX09739010, 2018ZX09301034003], the Science and Technology Program of Guangdong [2020B121202010]; the Science and Technology Planning Project of Guangzhou [201707020010], the Science, Technology and Innovation Committee of Shenzhen [GJHS20170314114526143, JSGG20180703155802047], the Economic, Trade and Information Commission of Shenzhen Municipality [20170505161556110, 20170505160926390, 201705051617070].

Dr. Xianhui Qin reports grants from the National Natural Science Foundation of China [81730019, 81973133].

Dr. Xiao Huang reports grants from the National Natural Science Foundation of China [81960074, 81500233], the Jiangxi Outstanding Person Foundation [20192BCBL23024], and Major Projects of the Science and Technology Department, Jiangxi [20171BAB205008].

No other disclosures were reported.

\section{Funding}

The study was supported by funding from the following: the National Key Research and Development Program [2016YFE0205400, 2018ZX09739010, 2018ZX09301034003]; the Science and Technology Program of Guangdong [2020B121202010]; the Science and Technology Planning Project of Guangzhou [201707020010]; the Science, Technology and Innovation Committee of Shenzhen [GJHS20170314114526143, JSGG20180703155802047]; the Economic, Trade and Information Commission of Shenzhen Municipality [20170505161556110, 20170505160926390, 201705051617070]; the National Natural Science Foundation of China [81730019, 81973133, 81960074, 81500233]; Jiangxi Outstanding Person Foundation [20192BCBL23024]and the Major projects of the 
Science and Technology Department, Jiangxi [20171BAB205008]. The funding bodies had no role in the study design, data collection, analysis and interpretation, and in the writing of the manuscript or in the decision to submit the manuscript for publication.

\section{Authors' contributions}

All authors contributed to the study. Lijing Ye performed the statistical analyses and wrote an initial draft of the paper. Xiping Xu, Binyan Wang, Xiaoshu Cheng and Genfu Tang conceptualized and designed the study, and supervised the survey. Fangrong Yan gave guidance on statistical methods. Yue Zhang, Jingyi Li and Nannan Cheng performed data and statistical analysis results checking. Other authors supervised and guided the writing of the manuscript. Thank for all authors have provided comments on drafts and contributed to the writing of the manuscript.

\section{Acknowledgements}

We thank the investigators and participants of the osteoporosis cohort study, the parent study, who made this report possible. Xiping Xu, the PI of the osteoporosis cohort study, has full access to all of the data in the study and takes responsibility for the integrity of the data and the accuracy of the data analysis.

\section{References}

1. Li, S., Meng, L., Chiolero, A., Ma, C. \& Xi, B. Trends in smoking prevalence and attributable mortality in China, 1991-2011. Prev Med 93, 82-87 (2016).

2. Chen, Z., et al. Contrasting male and female trends in tobacco-attributed mortality in China: evidence from successive nationwide prospective cohort studies. The Lancet 386, 1447-1456 (2015).

3. Yang, G., Wang, Y., Wu, Y., Yang, J. \& Wan, X. The road to effective tobacco control in China. The Lancet 385, 1019-1028 (2015).

4. Liu, S., et al. Prevalence and patterns of tobacco smoking among Chinese adult men and women: findings of the 2010 national smoking survey. J Epidemiol Community Health 71, 154-161 (2017).

5. Global Adult Tobacco Survey, China 2018.

6. Zhou, M., et al. Mortality, morbidity, and risk factors in China and its provinces, 1990-2017: a systematic analysis for the Global Burden of Disease Study 2017. The Lancet 394, 1145-1158 (2019).

7. Stacey A. Kenfield, S., Meir J. Stampfer, MD, DrPH, Bernard A. Rosner, PhD, Graham A. Colditz, MD, DrPH. Smoking and Smoking Cessation in Relation to Mortality in Women. JAMA 299(17):20372047(2008).

8. Nash, S.H., Liao, L.M., Harris, T.B. \& Freedman, N.D. Cigarette Smoking and Mortality in Adults Aged 70 Years and Older: Results From the NIH-AARP Cohort. Am J Prev Med 52, 276-283 (2017).

9. Jha, P., et al. 21st-Century Hazards of Smoking and Benefits of Cessation in the United States. $N$. Engl. J. Med. 368, 341-350 (2013). 
10. Choi, S.H. \& Stommel, M. Impact of Age at Smoking Initiation on Smoking-Related Morbidity and AllCause Mortality. Am J Prev Med 53, 33-41 (2017).

11. Zhi, K., et al. Trends in Cigarette Smoking Among Older Male Adults in China: An Urban-Rural Comparison. J. Appl. Gerontol. 38, 884-901 (2017).

12. Zhang, J., Ou, J.-X. \& Bai, C.-X. Tobacco smoking in China: Prevalence, disease burden, challenges and future strategies. Respirology 16, 1165-1172 (2011).

13. Rich, Z.C., Hu, M. \& Xiao, S. Gifting and sharing cigarettes in a rural Chinese village: a cross-sectional study. Tob Control 23, 496-500 (2014).

14. Lariscy, J.T., Hummer, R.A. \& Rogers, R.G. Cigarette Smoking and All-Cause and Cause-Specific Adult Mortality in the United States. Demography 55, 1855-1885 (2018).

15. Cho, M.H., et al. Effects of smoking habit change on all-cause mortality and cardiovascular diseases among patients with newly diagnosed diabetes in Korea. Scientific Reports 8(2018).

16. Banks, E., et al. Tobacco smoking and all-cause mortality in a large Australian cohort study: findings from a mature epidemic with current low smoking prevalence. BMC Med 13, 38 (2015).

17. Hsu, Y.H., et al. Large-scale genome-wide linkage analysis for loci linked to BMD at different skeletal sites in extreme selected sibships. J Bone Miner Res 22, 184-194 (2007).

18. Clinical Smoking Cessation Guidelines 2015.

19. Agudo, A., Ahrens, W., Benhamou, E., Benhamou, S., Boffetta, P., Darby, S. C., Simonato, L. Lung cancer and cigarette smoking in women: A multicenter case-control study in Europe. International Journal of Cancer 88(5), 820-827. (2000).

20. Christensen, C.H., et al. Association of Cigarette, Cigar, and Pipe Use With Mortality Risk in the US Population. JAMA Intern Med 178, 469-476 (2018).

21. Inoue-Choi, M., et al. Association of Long-term, Low-Intensity Smoking With All-Cause and CauseSpecific Mortality in the National Institutes of Health-AARP Diet and Health Study. JAMA Intern Med 177(2017).

22. Mons, U., et al. Impact of smoking and smoking cessation on cardiovascular events and mortality among older adults: meta-analysis of individual participant data from prospective cohort studies of the CHANCES consortium. BMJ 350, h1551 (2015).

23. Streppel, M.T., Boshuizen, H.C., Ocke, M.C., Kok, F.J. \& Kromhout, D. Mortality and life expectancy in relation to long-term cigarette, cigar and pipe smoking: the Zutphen Study. Tob Control 16, 107-113 (2007).

24. Lam, T.H., et al. High relative risk of all-cause mortality attributed to smoking in China: Guangzhou Biobank Cohort Study. PLoS One 13, e0196610 (2018).

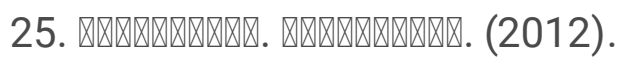

26. Jiang, Y., Elton-Marshall, T., Fong, G.T. \& Li, Q. Quitting smoking in China: findings from the ITC China Survey. Tob Control 19 Suppl 2, i12-17 (2010). 


\section{Tables}

Table 1. Baseline characteristics of the study participants by smoking status in male

\begin{tabular}{|c|c|c|c|c|c|}
\hline \multirow[t]{2}{*}{ Variables } & \multicolumn{3}{|c|}{ Smoking Status } & \multirow[t]{2}{*}{ Pvalue } & \multirow[t]{2}{*}{ Pvalue* } \\
\hline & Never $(n=990)$ & Former $(n=528)$ & Current $(n=3849)$ & & \\
\hline Age, y & $52.3(4.9)$ & $52.5(4.6)$ & $52.0(4.6)$ & 0.023 & 0.154 \\
\hline SBP, mmHg & $126.7(19.8)$ & $128.3(21.2)$ & $124.2(19.6)$ & $<0.001$ & $<0.001$ \\
\hline $\mathrm{DBP}, \mathrm{mmHg}$ & $81.1(12.0)$ & $82.2(12.6)$ & 79.5 (11.9) & $<0.001$ & $<0.001$ \\
\hline $\mathrm{BMI}, \mathrm{kg} / \mathrm{m}^{2}$ & $21.5(2.6)$ & $22.0(2.8)$ & $21.0(2.4)$ & $<0.001$ & $<0.001$ \\
\hline Glucose & $98155.9 .3)^{8}$ & 971249.4 .7 & 9613.89 .59 & $<0.001$ & $<0.001$ \\
\hline Total cholesterol & 171 192.6) & $172,95(15.0)^{4.3}$ & $168,899.5)^{48.5}$ & $<0.001$ & 0.207 \\
\hline Triglycerides & 861996.85 .5 & 891227.9 .0 & $8214(6.4)^{9}$ & $<0.001$ & 0.029 \\
\hline $\begin{array}{l}\text { High density } \\
\text { fipoprotein }\end{array}$ & 53.64 .645 .2 & 54.65 .05 .6 & $54.5(45.2,65.4)$ & 0.384 & 0.072 \\
\hline $\begin{array}{l}\text { Atgohol Status, No. } \\
\text { Never }\end{array}$ & $670(67.7)$ & $225(42.6)$ & 1947 (50.7) & $<0.001$ & \\
\hline Former & $17(1.7)$ & $40(7.6)$ & $98(2.6)$ & & \\
\hline Current & $303(30.6)$ & $263(49.8)$ & $1792(46.7)$ & & \\
\hline $\begin{array}{l}\text { Foducation Level } \\
\text { nlliterate }\end{array}$ & $212(21.5)$ & 114 & $960(25.0)$ & $<0.001$ & \\
\hline Elementary school & $457(46.4)$ & $270(51.3)$ & $1947(50.8)$ & & \\
\hline Middle school and & $316(32.1)$ & $142(27.0)$ & $928(24.2)$ & & \\
\hline Pccupation Type, & $874(88.4)$ & $477(90.5)$ & $3540(92.1)$ & 0.001 & \\
\hline 羕stofyension, & $62(6.3)$ & $48(9.1)$ & $146(3.8)$ & $<0.001$ & \\
\hline 伃bety, yes(\%) & $11(1.1)$ & $1(0.2)$ & $13(0.3)$ & 0.004 & \\
\hline
\end{tabular}

Abbreviations: BMI, body mass index; DBP, diastolic blood pressure; HDL, high-density lipoprotein; SBP, systolic blood pressure. For continuous variables, values are presented as mean (SD) and mean (SE).. Laboratory results are presented as median (IQR). *The differences between never smokers and the current smokers was corrected by the Bonferoni method.

Table 2. The association between smoking status and mortality in male 


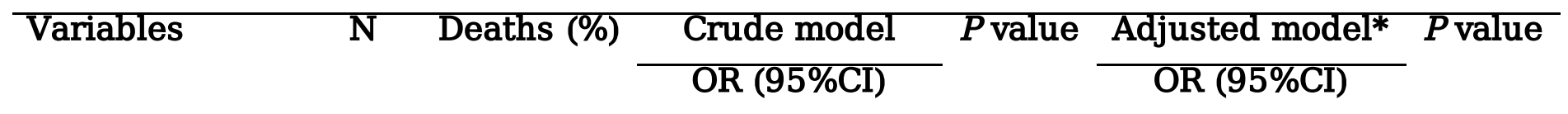

\section{Smoking Status}

$\begin{array}{llllr}\text { Never } & 990 & 74(7.5) & \text { ref ref }\end{array}$

$\begin{array}{lcccccc}\text { Former } & 528 & 75(14.2) & 2.05(1.46,2.88) & <0.001 & 2.12(1.49,3.01) & <0.001 \\ \text { Current } & 3849 & 430(11.2) & 1.56(1.20,2.01) & <0.001 & 1.60(1.23,2.08) & <0.001\end{array}$

Pack-years

Current

$\begin{array}{lcccccc}<20 & 960 & 82(8.5) & 1.16(0.84,1.60) & 0.378 & 1.18(0.85,1.64) & 0.314 \\ 20-40 & 2148 & 245(11.4) & 1.59(1.22,2.09) & <0.001 & 1.69(1.28,2.23) & <0.001 \\ \geq 40 & 741 & 103(13.9) & 2.00(1.46,2.74) & <0.001 & 1.85(1.33,2.56) & <0.001\end{array}$

*Adjusted for age, body mass index, systolic blood pressure, diastolic blood pressure, fasting glucose, total cholesterol, triglycerides, high-density lipoprotein cholesterol and alcohol drinking status, education level and occupation .

Table 3. The relation of smoking initiation age and pack-years with mortality in current smokers

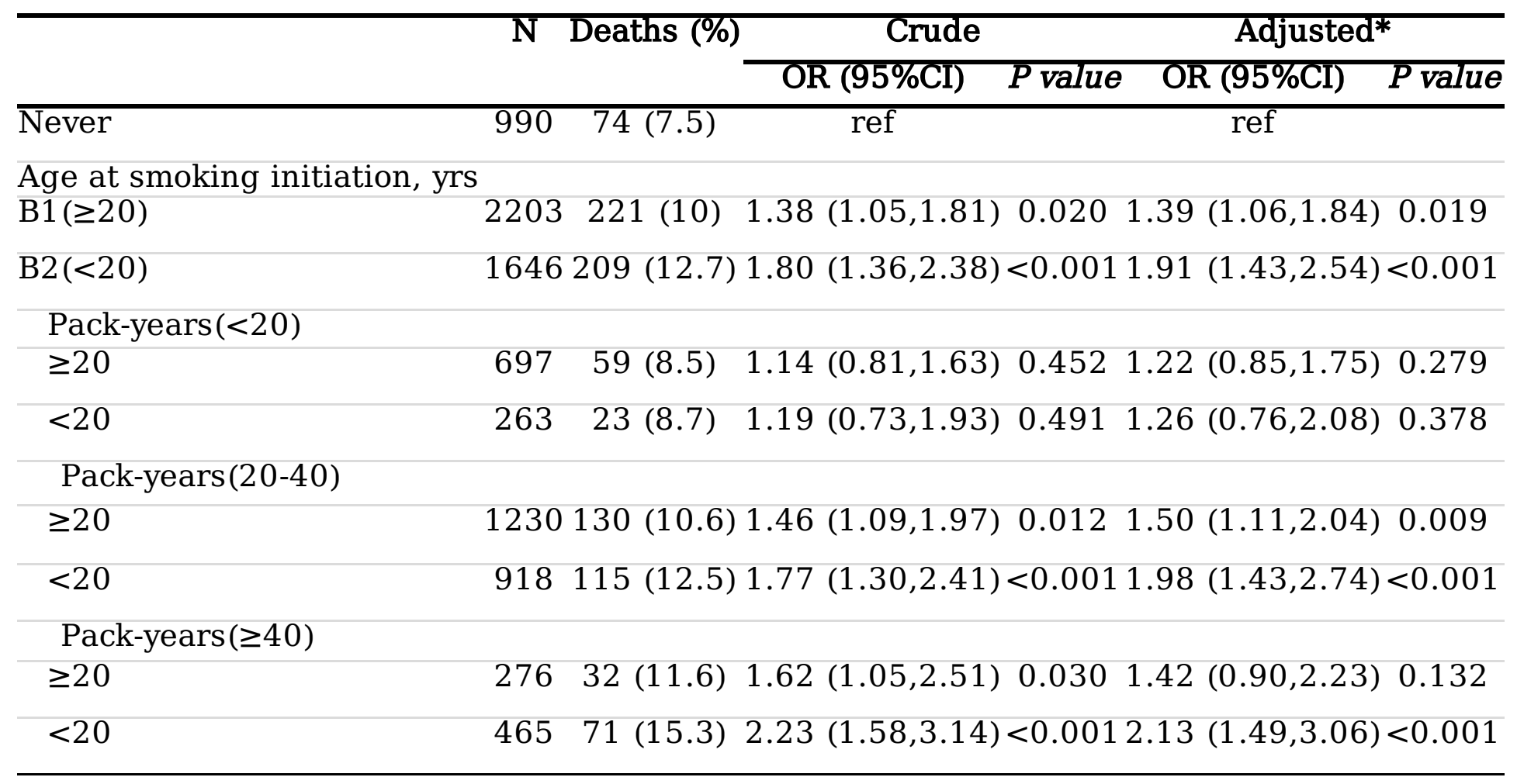

*Adjusted for age, body mass index, systolic blood pressure, diastolic blood pressure, fasting glucose, total cholesterol, triglycerides, high-density lipoprotein cholesterol and alcohol drinking status, education level and occupation.

Table 4. The relation of smoking cessation age and pack-years with mortality in former smoker 
Smoking Status

Never

Age at cessation, yrs

$<55$

46559 (12.7)

1.80

$(1.25,2.59)$

0.002

2.20

$(1.49,3.27)<0.001$

$\geq 55$

$6316(25.4)$

$(2.29,7.75)<0.0012 .22(1.45,3.41)$

0.004

pack-years

$(<\operatorname{median}(26))$
$<55$
24632 (13.0) 1.85
$(1.19,2.88)$
0.006
$2.66(1.63,4.33)<0.001$
$\geq 55$
$10 \quad 4(40.0)$
8.25
0.001
3.96
0.045
$(2.28,29.85)$
$(1.03,15.14)$

pack-years

( $\geq$ median(26))
$<55$
21927 (12.3) 1.74
$(1.09,2.78)$
0.020
1.94
$(1.18,3.20) \quad 0.009$
$\geq 55$
$53 \quad 12(22.6) \quad 3.62$
$(1.84,7.13)<0.001$
$2.58(1.18,5.63)$
0.018

*Adjusted for age, body mass index, systolic blood pressure, diastolic blood pressure, fasting glucose, total cholesterol, triglycerides, high-density lipoprotein cholesterol and alcohol drinking status, education level and occupation.

Table 5. The joint effect between drinking and smoking on mortality in males

\begin{tabular}{|c|c|c|c|c|c|c|}
\hline \multirow{3}{*}{$\begin{array}{c}\text { Drinking } \\
\text { Status }\end{array}$} & \multicolumn{6}{|c|}{ Smoking Status } \\
\hline & \multicolumn{2}{|c|}{ Never } & \multicolumn{2}{|c|}{ Former } & \multicolumn{2}{|c|}{ Current } \\
\hline & $\begin{array}{c}\text { Deaths } \\
(\%)\end{array}$ & OR $(95 \% \mathrm{CI})$ & $\begin{array}{c}\text { Deaths } \\
(\%)\end{array}$ & OR $(95 \% \mathrm{CI})$ & $\begin{array}{c}\text { Deaths } \\
(\%)\end{array}$ & OR (95\%CI) \\
\hline Never & $58(8.7)$ & $R e f$ & $35(15.6)$ & $\begin{array}{c}2.18(1.37 \\
3.48)\end{array}$ & $\begin{array}{c}204 \\
(10.5)\end{array}$ & $\begin{array}{c}1.31(0.95, \\
1.80)\end{array}$ \\
\hline Former & $1(5.9)$ & $\begin{array}{c}0.66(0.09 \\
4.65)\end{array}$ & $14(35.0)$ & $\begin{array}{c}6.40 \\
(3.03,13.50)\end{array}$ & $22(22.4)$ & $\begin{array}{c}2.56(1.47) \\
4.47)\end{array}$ \\
\hline Current & $15(5)$ & $\begin{array}{c}0.58(0.32, \\
1.05)\end{array}$ & $26(9.9)$ & $\begin{array}{c}1.23(0.74 \\
2.04)\end{array}$ & $\begin{array}{c}203 \\
(11.3)\end{array}$ & $\begin{array}{c}1.39(1.00, \\
1.93)\end{array}$ \\
\hline
\end{tabular}

P for interaction $=0.034$

Adjusted for age, body mass index, systolic blood pressure, diastolic blood pressure, fasting glucose, total cholesterol, triglycerides, high-density lipoprotein cholesterol, alcohol drinking status, education level and occupation.

\section{Figures}


A

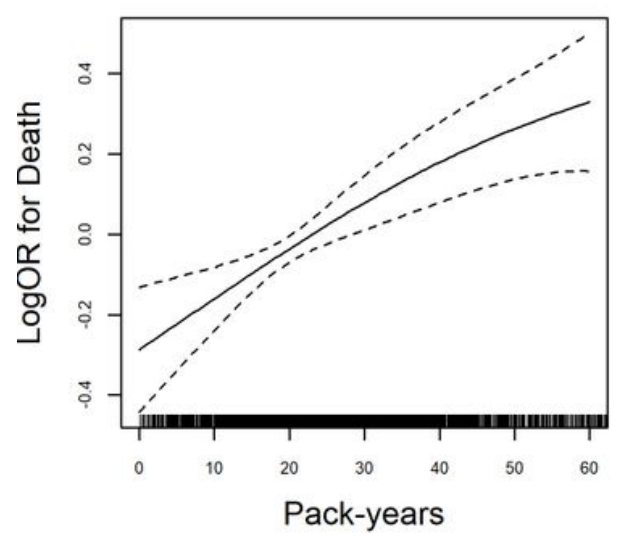

B

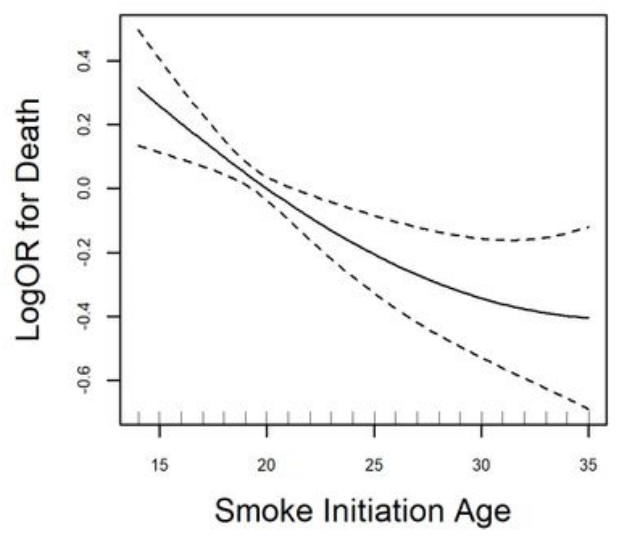

C

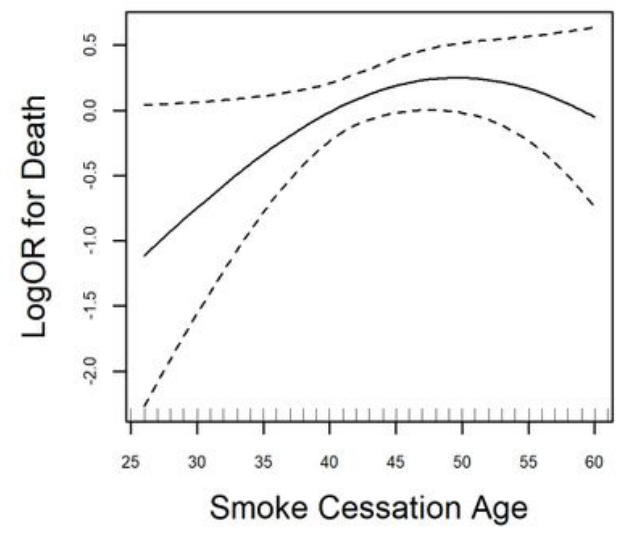

Figure 1

Smooth curves between smoking status and death.

\section{Supplementary Files}

This is a list of supplementary files associated with this preprint. Click to download.

- Supplementalfigureflowchart.tif

- SupplementalTable.docx 